\title{
New ammunition in the fight to label unhealthy foods
}

\author{
Cite as: CMAJ 2018 January 8;190:E25. doi: 10.1503/cmaj.109-5540
}

Posted on cmajnews.com on Dec. 13, 2017.

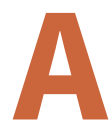

s Canada prepares to introduce warnings on foods high in sugar, sodium and saturated fat, a United Nations commission is lending its power to protect such initiatives from running afoul of trade agreements.

The Codex Alimentarius Commission, a trade body of more than 180 member nations, has begun work on global standards for front-of-package nutrition labelling, with new guidelines expected in the next three to five years.

Diet-related risks combined with physical inactivity are estimated to cause nearly one in five deaths worldwide. A few countries, including the United Kingdom and Chile, have introduced simplified nutrition labels on the front of packages to warn consumers about unhealthy foods. But without the protection of shared standards, these efforts have become the focus of several international disputes, with some countries and food companies contending that the health warnings restrict trade.

Codex Alimentarius standards are often a deciding factor in food trade disputes, explained Bill Jeffery, a public interest lawyer and official observer at the commission. However, he noted the standards tend to be conservative. "It's not a forum where public health rhetoric is very popular."

The global talks come at a crucial time for Canada, which is poised to announce draft warning labels for foods that contain more than $15 \%$ of the daily value for sugar, sodium or saturated fat. The initiative has been divisive, drawing praise from health advocates and the ire of industry.

During fall consultations, health experts advocated for an approach based on Chile's system of stop-sign-shaped warnings. According to Fabio da Silva Gomes of the Pan

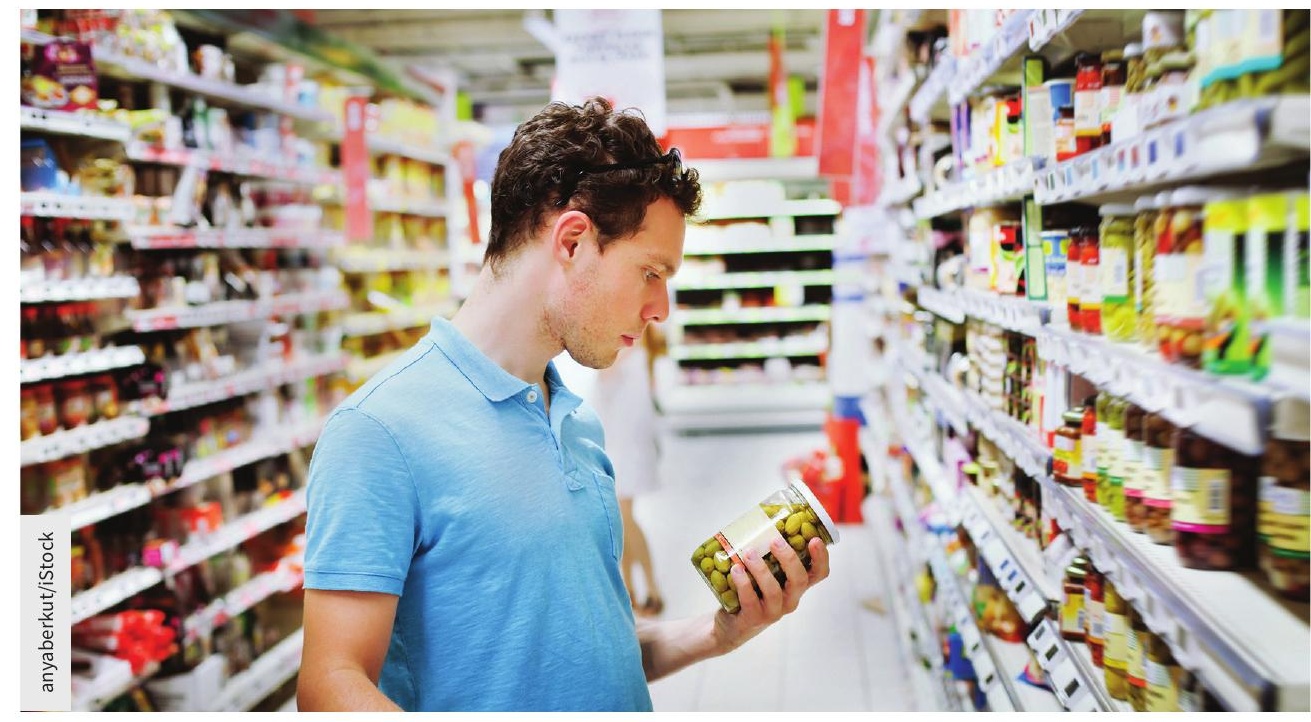

With nearly one in five deaths attributed to diet-related risks, there's growing momentum for frontof-pack warnings on foods high in sugar, salt and fat.

American Health Organization, surveys show that the warnings influenced more than $91 \%$ of consumers, and pushed food companies to reformulate $18 \%$ of products.

Health Canada appeared to favour the Chilean approach, initially proposing warning designs that incorporated stop and yield symbols. However, food industry representatives said these designs were too alarming and too similar to poisonous hazard symbols. Some argued that nutrition information should be presented without interpretation and proposed using a magnifying lens symbol to direct consumers to the nutrition facts table.

David Hammond, a professor of public health at the University of Waterloo, countered that most Canadians don't understand the nutrition facts table; less than a quarter are able to correctly identify calorie amounts. Health Canada is now considering four designs: one with circles (instead of stop signs), one with a triangle (instead of a yield sign), and two featuring the industryapproved magnifying lens. Jeffery wonders if this reflects an attempt to court support from the food industry. At a November meeting, "industry representatives outnumbered academics 38 to 2 , and health groups 38 to 17," he said.

Jeffery also raised concerns about the government's narrow focus on sugar, sodium and saturated fat. Four times as many nutrition-related deaths are linked to diets low in fruits, vegetables, whole grains and other ingredients, he explained. Failing to take these factors into account might lionize nutritionally vacuous foods, while disparaging nutritious foods with slightly high levels of sugar, salt or fat. If the scheme makes diet cola look good, but slaps a warning on nuts with some salt, for example, "it will do us a great disservice," he said.

Lauren Vogel, CMAJ 